\title{
Notícia: VI Conferência Internacional Sobre Filosofia, Psiquiatria e Psicologia - "Ética, Linguagem e Sofrimento"
}

\author{
Ileno Izídio da Costa $^{1}$ \\ Universidade de Brasília

\section{News: VI International Conference on Philosophy, Psychiatry and Psychology - "Ethics, language and suffering"}

Em 1996, um grupo de filósofos, psiquiatras, psicólogos e profissionais de saúde mental interessados em aprofundar a discussão filosófico-prática sobre suas atuações se reuniu em Marbella, na Espanha, iniciando um ciclo de conferencias sobre Filosofia e Saúde Mental. Mais que um grupo internacional, a realização destas conferências passou a representar um movimento de profissionais, acadêmicos e pesquisadores empenhados em desenvolver a interdisciplinaridade, o debate e o desenvolvimento de suas áreas de conhecimento.

Até a presente data já ocorreram as conferências da Espanha (1st International Conference on Philosophy and Mental Health, Marbella, 1996), da França (2 $2^{\text {nd: }}$ "Vulnerability \& Destiny: about the Phenomenology of Schizophrenia", Marseille, 1997; $3^{\text {rd } .: ~ " S c h i z o p h r e n i a ~ a n d ~ I d e n t i t y ", ~ N i c e, ~}$ 1999; $5^{\text {th }} .:$ "Pain and Depression", Paris, 2001) e Itália (4 $4^{\text {th }} .:$ "Madness, Science and Society", Florence, 2000). Em Paris (2001), os Professores Drs. Ileno Izídio da Costa e Francisco Martins foram escolhidos os próximos organizadores deste evento internacional que será realizado pela primeira vez na América Latina, no Brasil e em Brasília!

Do título geral sobre Saúde Mental evoluiu para Filosofia, Psiquiatria e Psicologia, tornando-se o Movimento Internacional PPP (Philosophy, Psychiatry and Psychology). Destes encontros, algumas realidades começaram a se modificar, tais como:

Novos grupos acadêmicos têm sido constituídos em muitas partes do mundo, incluindo Austrália, Dinamarca, Inglaterra, Finlândia, França, Alemanha, Holanda, Itália, Japão, Nova Zelândia, Noruega, Romênia, Rússia, Escócia, África do Sul, América do Sul (Brasil e Argentina, p.ex.), Suécia, Turquia, Reino Unido e Estados Unidos;.

Tem havido uma rápida expansão em termos de números de filósofos e profissionais que estão contribuindo para a rápida expansão para esta nova disciplina. Os grupos Britânico e Norte Americano têm uma filiação combinada que cuja soma ultrapassa 2.500 participantes;

Um novo jornal internacional (PPP - Philosophy, Psychiatry, and Psychology) tem sido mantido pelos grupos Britânico e Norte Americano através da The Johns Hopkins University Press. Apoiado por um forte Corpo Editorial, representando muitos dos grupos nacionais e coordenado

1 Professor Adjunto do Departamento de Psicologia Clínica, Coordenador do Centro de Atendimento e Estudos Psicológicos-CAEP/IP. Campus Universitário Darcy Ribeiro, Gleba A, ICC Sul, 70-910-900, Brasília/ DF.E-mail: ileno@unb.br pela Baronesa Mary Warnock (Reino Unido), o jornal PPP já está em seu nono ano de existência;

- Três novas séries internacionais de livros foram lançadas: Philosophical Psychopathology (pela MIT Press, USA), International Perspectives in Philosophy and Psychiatry (pela Oxford University Press, UK), e Psychiatrie en Filosofie (pela BOOM Publishers, The Netherlands);

- A primeira "cadeira" profissional para Filosofia e Saúde Mental foi estabelecida na Universidade de Warwick, no Reino Unido. O grupo de Warwick mantém programas de Mestrado, Doutorado (PhD) e de pesquisa. Tem havido um razoável número de outras iniciativas de curso e pesquisa pelo mundo afora;

- Programas de serviços educacionais em aspectos relevantes da filosofia têm sido desenvolvidos e direcionados para profissionais da saúde mental (enfermeiros, assistentes sociais, psicólogos, etc), em parceira com Sainsbury Centre for Mental Health e a Warwick University, no Reino Unido;

- Uma nova categoria de referência: "filosofia da psiquiatria" tem sido adotada como uma categoria distinta citada pelo principal índice de publicações filosóficas, o Philosopher's Index, e a WPA (World Psychiatric Assotiation) criou recentemente a sua seção filosófica;

- Próximas Conferências Internacionais: já estão sendo planejadas as próximas conferências a acontecer na Alemanha (2004), nos Estados Unidos (2005) e na Holanda (2006);

- Na América Latina: Realização de Conferências Internacionais sobre Psicologia e Psiquiatria Fenomenológica e Análise Existencial, desde 1992, em Buenos Aires (Argentina) e Jornadas sobre Psicopatologia e Linguagem pelo Laboratório de Psicopatologia e Psicanálise da Universidade de Brasília (Brasil).

Esta VI Conferência visa reanimar e reativar três grandes esquecimentos do século findo, por temermos que eles se prolonguem ao longo do presente século: a Ética, a Linguagem e o Ser humano em sofrimento. Entendemos que essa grosseira amnésia se apresenta também como disfarce, engano e até cinismo, e é promotora efetiva de sofrimento nos domínios da Psicologia, da Psiquiatria, da Filosofia, estendendo-se certamente para outras disciplinas e setores da vida. O esquecimento ético se revela em todos os domínios da vida humana, especialmente todas as práticas sociais e descalabros da falta de cuidado no trabalho com o ser humano em todos os seus sentidos. O esquecimento da linguagem, na sua plenitude, se mostra naquilo que é constitutivo mesmo do humano e dá espaço à interrogação filosófica da clínica 
psiquiátrica, psicológica, psicanalítica e social enquanto mediada pela palavra. O Ser humano em sofrimento, justamente por ter um corpo efetivo material, mas que é fonte de desejo, de atividade e de compartilhamento, portanto portador de sofrimento, também tem sido esquecido.

Esta discussão dar-se-á através de Conferências Magnas (nacionais e internacionais), Simpósios, Mesas Redondas e apresentação de pôsteres, além de eventos paralelos tais como lançamentos de livros, mini-cursos e exposições em estandes da área. Convidamos a todo(a)s a não só participar como também a contribuir para a efetiva problematização dos temas afins. Agende.

Data: 02 a 05 de julho de 2003

Local: Brasília/DF.

Promoção e Organização:

Universidade de Brasília - UnB/Instituto de Psicologia - IP e Associação Brasileira para o Avanço Conjunto da Filosofia, Psicopatologia e Psicoterapia - ABRAFIPP

Homepage: http://www.unb.br/ip/ppp03

E-mail: ppp03@unb.br 